\title{
Protection from Staphylococcus aureus mastitis associated with poly- $N$-acetyl $\beta-1,6$ glucosamine specific antibody production using biofilm-embedded bacteria
}

\author{
M. M. Pérez ${ }^{a, b}$, A. Prenafetac ${ }^{c}$ J. Valle ${ }^{d}$, J. Penadés ${ }^{e}$, C. Rota ${ }^{f}$, C. Solanod, J. Marcog, M.J. \\ Grillód $^{d}$ I. Lasad, J.M. Irache ${ }^{h}$, T. Maira-Litran', J. Jiménez-Barbero', L. CostaC ${ }^{\mathrm{C}}$, G.B. Pier ${ }^{i}$, D. \\ de Andrés ${ }^{d}$, and $B$. Amorena $a, d$ \\ aDepartamento de Sanidad Animal, SIA-CITA (DGA) Ctra. de Montañana, Zaragoza, Spain

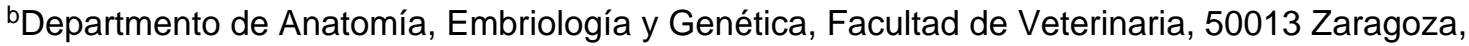 \\ Spain \\ 'Laboratorios HIPRA S.A., 17170 Amer, Girona, Spain \\ dInstituto de Agrobiotecnología, CSIC-Universidad Pública de Navarra-Gobierno de Navarra, \\ 31192 Mutilva Baja, Spain \\ eInstituto Valenciano de Investigaciones Agrarias, 46113 Moncada, Valencia, Spain \\ fDepartamento de Producción Animal y Ciencia de los Alimentos, Facultad de Veterinaria, 50013 \\ Zaragoza, Spain \\ gLaboratorio Normativo de Salud Pública, Departamento de Sanidad, Gobierno Vasco, 48010 \\ Bilbao, Spain \\ hCentro Galénico, Universidad de Navarra, 31080 Pamplona, Spain \\ 'Channing Laboratory Brigham and Women's Hospital, Harvard Medical School, Boston, MA \\ 02115, USA \\ iCentro de Investigaciones Biológicas, CSIC, 28040 Madrid, Spain
}

\begin{abstract}
Staphylococcus aureus vaccines based on bacterins surrounded by slime, surface polysaccharides coupled to protein carriers and polysaccharides embedded in liposomes administered together with non-biofilm bacterins confer protection against mastitis. However, it remains unknown whether protective antibodies are directed to slime-associated known exopolysaccharides and could be produced in the absence of bacterin immunizations. Here, a sheep mastitis vaccination study was carried out using bacterins, crude bacterial extracts or a purified exopolysaccharide from biofilm
\end{abstract}

\footnotetext{
(C) 2009 Elsevier Ltd. All rights reserved.

Corresponding author: Beatriz Amorena, ${ }^{\mathrm{I}}$ Instituto de Agrobiotecnología, CSIC-Universidad Pública de Navarra-Gobierno de Navarra, 31192 Mutilva Baja, Spain. Phone: +34 9481680 06; Fax: + 3494823 21 91; bamorena@unavarra.es.

Publisher's Disclaimer: This is a PDF file of an unedited manuscript that has been accepted for publication. As a service to our customers we are providing this early version of the manuscript. The manuscript will undergo copyediting, typesetting, and review of the resulting proof before it is published in its final citable form. Please note that during the production process errors may be discovered which could affect the content, and all legal disclaimers that apply to the journal pertain.

Disclosed potential conflicts of interest

Drs. T. Maira-Litran and G.B. Pier declare they have a financial interest in the form of licensing and consulting income for the commercial development of PNAG-based vaccines and immunotherapies related to issued U.S. patents 7,252,828, 7,015,007, 6,743,431, 6,399,066, 5,980,910, and published U.S. patent applications 20050118198 and 20040175731.
} 
bacteria delivered in different vehicles. This polysaccharide reacted specifically with antibodies to poly- $N$-acetyl- $\beta$-1,6-glucosamine (PNAG) and not with antibodies to other capsular antigens or bacterial components. Following intra-mammary challenge with biofilm-producing bacteria, antibody production against the polysaccharide, milk bacterial counts and mastitis lesions were determined. Bacterins from strong biofilm-producing bacteria triggered the highest production of antibodies to PNAG and conferred the highest protection against infection and mastitis, compared with weak biofilm-producing bacteria and non-cellular inocula. Thus, bacterins from strong biofilm bacteria, rather than purified polysaccharide, are proposed as a cost-efficient vaccination against $S$. aureus ruminant mastitis.

\section{Keywords}

S. aureus; poly- $N$-acetyl $\beta-1,6$ glucosamine; Antibody; Mastitis; Vaccine

\section{Introduction}

Staphylococcus aureus adhesins are involved in the establishment of infection through early attachment to host tissues [1]. A second step in virulence results in intercellular adhesion among bacterial cells and subsequent development of a biofilm, leading to chronic infections and bacterial resistance to phagocytosis $[2,3,4]$. A major constituent of the staphylococcal biofilm matrix is the poly- $N$-acetyl $\beta-1,6$ glucosamine surface polysaccharide, synthesized by proteins encoded by the intercellular adhesion ica operon [5]. This homopolymer has been named PIA, polysaccharide intercellular adhesin, in S. epidermidis [6] and PNAG in S. aureus [7]. Another, though less frequent biofilm constituent among mastitis isolates is the Bap protein [8]. In S. aureus studies, PNAG exopolysaccharide conjugated to diphtheria toxin has been proposed as a vaccine candidate in laboratory animals against systemic infection [9]. The results showed a protective effect [10]. This conjugate-vaccine strategy may be useful in humans but may not be cost-efficient for staphylococcal ruminant mastitis.

Different vaccination strategies involving surface polysaccharides have been evaluated for efficacy against staphylococcal mastitis in ruminants, encompassing inactivated bacteria and toxoids [11]; bacteria surrounded by a mucous substance (likely a biofilm matrix) termed a pseudo-capsule [12] or slime [13]; capsular polysaccharide (CP), types CP5, CP8 and CP336 linked to protein carriers [14,15,16]; CP5 co-entrapped in liposomes with alpha-toxin [17]; and a mixture of slime in liposomes, toxoid and different inactivated bacteria [18]. Several field trials with these and other vaccines including bacterin-toxoid [19,20,21], crude extracts of encapsulated bacteria in aluminum hydroxide [22,23], have revealed a significant degree of protection against mastitis. One of the main goals in vaccination against mastitis is to obtain reduced inflammation at the site of injection, high efficiency against disease, a cost-efficient bacterial inoculum and an immunological parameter that could help to predict the success of vaccination.

Data on the specific role of biofilm matrix polysaccharides in the development of a protective immune response against $S$. aureus mastitis are limited. Here, we used different vaccine preparations and performed a comparative immunization-challenge study against $S$. aureus mastitis in sheep. Immunization was done with: a) cell-free surface polysaccharide (PNAG), purified or in the form of cell extracts, in different vehicles (liposomes, microparticles or aluminum hydroxide); b) $S$. aureus unbound cells (not within biofilm) in adjuvant (aluminum hydroxide); or c) $S$. aureus cells embedded in their biofilm matrix in different adjuvants. This study demonstrated that vaccination with whole bacterial cells surrounded by their own biofilm matrix containing PNAG conferred protection against $S$. aureus infection and mastitis. This protection was related to the level of antibodies to $S$. 
aureus PNAG and to the degree of biofilm formation and PNAG production of the immunizing strain, and was independent of the adjuvant and CP type of the challenge strain. This information may be relevant to mastitis vaccine design and identification of an immune correlate associated with protection against mastitis.

\section{Materials and Methods}

\subsection{Bacterial cultures for enrichment of adherent bacteria}

Four S. aureus isolates of different CP types were used in the immunization study (Table 1). Originally, they all had a moderate-to-weak biofilm production capacity, being assigned to the group of "weak biofilm phenotype" bacteria, even though they all were ica-positive. To enhance biofilm production, repeated bacterial cultures were grown at $37^{\circ} \mathrm{C}$ in Tryptic Soy Broth (TSB) or Tryptic Soy Agar (TSA) supplemented with glucose (2\%, w/v) (TSA-G, Panreac). At the end of the process, the adherent bacteria were able to produce rough colonies on Congo red agar (TSA-G supplemented with $0.08 \%$ Congo Red; [24]) and produced a "strong biofilm phenotype" $[8,24]$, as assessed by polystyrene adherence tests [25] (see below).

\subsection{Hyperimmune serum}

Hyperimmune serum was produced in Rasa Aragonesa adult sheep for detection of PNAG. For this, intramuscular immunizations were done with ATCC29213 strong biofilm phenotype bacteria embedded in biofilm and adjuvant $\left(10^{10}\right.$ heat-killed bacteria emulsified in incomplete Freund adjuvant) [26]. Some serum aliquots were absorbed with $S$. aureus Newman (weak biofilm phenotype, CP5 strain) to remove antibodies to CP5 and common cell surface components. This absorption had a minimal effect on removal of PNAG antibodies. Alternatively, serum was absorbed with non-encapsulated (CP-negative) bacteria (S. aureus JL252, a weak biofilm phenotype strain derived from the CP8-Becker strain but genetically modified so as to not express CP; kindly provided by J.C. Lee, Brigham and Women's Hospital, Harvard Medical School). The efficiency of absorptions was verified by double agar gel immunodiffusion (AGID) and immunoelectrophoresis (IEP) assays.

\subsection{Preparation of crude bacterial extracts}

Crude bacterial extracts were prepared [27]. Briefly, $500 \mu \mathrm{l}$ of an overnight culture (18 h) of each isolate were spread on a TSA-G plate which was incubated for $24 \mathrm{~h}$ at $37^{\circ} \mathrm{C}$. Bacteria were autoclaved at $121^{\circ} \mathrm{C}$ for $60 \mathrm{~min}$. Cells and cell debris were removed by centrifugation $(10,000 \times g$ for $60 \mathrm{~min})$. The pellet was diluted in PBS and the autoclaving and centrifugation steps were repeated. The supernatants were pooled, dialyzed against deionized water for $48 \mathrm{~h}$ at $4{ }^{\circ} \mathrm{C}$, passed through $0.22 \mu \mathrm{m}$ filters and lyophilized.

\subsection{Agar gel and dot blot serologic tests}

AGID test was used as previously described $[28,29]$ and precipitin lines were examined at 24 and $48 \mathrm{~h}$. For IEP, antigens from the bacterial extracts were separated by electrophoresis in $1 \%$ agarose gels (pH 8.3). Purified PNAG and the antibody to deacetylated PNAG (dPNAG) were used as antigen positive controls [30]. Following electrophoresis, the antiserum (a hyperimmune serum against $S$. aureus ATCC29213 of strong biofilm phenotype or anti-PNAG antibodies) diffusion was allowed for $24 \mathrm{~h}$. The precipitin lines in IEP disappeared upon treatment of crude extracts with sodium metaperiodate (Fluka) due to carbohydrate oxidation of the antigen [31] (not shown). The PNAG immunological specificity of the polysaccharide preparation was further analyzed by dot-blot [5] using antibodies previously described [7]. 


\subsection{PNAG purification}

PNAG was purified according to established procedures [10]. Alternatively, to separate it from CP, crude extract was fractionated on a HiLoad TM 16/10 Q Sepharose column fast flow anion exchange chromatography (Pharmacia), using $0.02 \mathrm{M} \mathrm{HCl}$-Tris buffer (pH 8). Fractions were concentrated and the presence of PNAG detected by IEP using antiserum against strong biofilm phenotype bacteria. PNAG-containing fractions were pooled, treated overnight with proteinase $\mathrm{K}\left(1 \mathrm{mg} / \mathrm{mL} ; 37^{\circ} \mathrm{C}\right)$, dialyzed against distilled water and lyophilized.

\subsection{Quantification of PNAG by inhibition ELISA and indirect ELISA}

PNAG was quantified in bacterial extracts by an ELISA inhibition method using anti-PNAG antiserum (described in section 2.2) absorbed with $S$. aureus strain Newman (being CP5 and a weak biofilm phenotype strain), purified PNAG-coated wells and protein $\mathrm{G}$ conjugated with peroxidase. Data (sample dilution producing 50\% inhibition) were analyzed with a linearity test using the Logit and Log transformations [32]. The indirect ELISA was carried out like the inhibition ELISA, except that $100 \mu \mathrm{l}$ of serum from hyperimmunized animals (Section 2.5) was used as primary antibody.

\subsection{Vaccination, challenge and analysis of sheep}

To determine the immunogenicity and efficacy against infection, a total of 81 healthy pregnant Rasa Aragonesa sheep lacking detectable serum antibodies against Staphylococcus were randomly allotted into ten experimental groups. Nine of these groups $(\mathrm{n}=65)$ were immunized and challenged (Section 2.7.1). After challenge, animals were analyzed according to immunological, bacteriological and pathological criteria (Section 2.7.2). An additional (control) group $(\mathrm{n}=16)$ of non-vaccinated sheep was examined, challenged, examined and maintained under the same experimental conditions. Animal handling and experimental procedures were in accordance with European directives (DOCE 86/609/EEC), and approved and supervised by the Ethical Committee of the Institution.

2.7.1. Sheep Immunization and challenge-Different immunization approaches were undertaken, as specified in Table 2. Bacterins containing bacteria embedded in PNAG containing matrix, anion-exchange purified PNAG or crude extracts containing PNAG were used. For bacterin inocula (bacteria surrounded by a PNAG containing matrix), S. aureus ATCC29213 or C104 were independently used. The capsular type of both bacterial isolates was different from that of the challenge isolate S. aureus C195 (CP8), in order to ensure that the effect of vaccination was not attributable to $\mathrm{CP}$ immune response. Bacterins containing bacteria in strong biofilms (enriched for biofilm production) corresponded to Groups 1, 3 ( $S$. aureus ATCC29213) and 2 (S. aureus C104). Bacterins containing free (non-biofilm) bacteria of a weak biofilm phenotype (not enriched for biofilm production) corresponded to Groups 4 (S. aureus ATCC29213) and 5 (S. aureus C104) and were used for comparative purposes. As adjuvants, four of these groups (1,2, 4 and 5) received aluminum hydroxide, and group 3 received a commercial adjuvant (Laboratorios HIPRA S.A.). Bacterium-free PNAG (soluble antigen hereafter) was used as follows: a) purified and mixed with liposomes and an E. coli bacterin (Laboratorios HIPRA S.A.) (Group 6); b) in the form of crude extract mixed with liposomes (Group 7); c) purified and delivered in microparticles (Group 8); or d) purified and mixed with liposomes (Group 9). Animals inoculated with PBS were used as non-immunized controls.

Animals were immunized twice five weeks apart, carrying out the first immunization at 3.5 months of pregnancy. Groups 1, 2, 4, 5, 7 and 9 were immunized intramuscularly, like in our previous study [18], and groups 3, 6 and 8 were immunized subcutaneously, following recommendations for use of the specific delivery systems and the non-staphylococcal part of 
the inoculum. According to the intra-group variance expected in the parameters analysed, the number of sheep used for immunization or control groups ranged from 5 to 16 sheep (i.e. $\mathrm{n}=8$ in groups $1-5 ; \mathrm{n}=5$ in groups $6-8 ; \mathrm{n}=10$ in group 9 ; and $\mathrm{n}=16$ in control group).

Preparations of bacterin inocula (groups 1-5) consisted of $10^{10}$ bacteria per inoculum, per bacterial isolate, obtained as indicated below, using $1 \mathrm{~mL}$ of aluminum hydroxide (3\%o) or 1 $\mathrm{mL}$ of commercial adjuvant (from Laboratorios HIPRA S.A.) as adjuvants and S. aureus ATCC29213 (CP5) or C104 (CP non-typable) as specified in Table 2. For cell-free PNAG inocula, $2 \mathrm{mg}$ of PNAG (obtained by ion exchange chromatography) were used in all the sheep groups. This amount of PNAG was inoculated in one sheep group in the form of crude bacterial extracts (15 mg) from strong biofilm phenotype $S$. aureus ATCC29213 (CP5) and 76 (CP8), that were mixed with liposomes in a final mixture of $30 \mathrm{mg}$ (group 7). Liposomes were produced as described previously [33]. Alternatively, purified PNAG (2 mg) was used: a) mixed 1:1 (vol/vol) with liposomes (group 9); b) mixed 1:1 (vol/vol) with liposomes and also including in the inoculum $1 \mathrm{~mL}$ of an Escherichia coli bacterin (Laboratorios HIPRA S.A.) (group 6); or c) included in microparticles prepared at the Galenic Center of the University of Navarra (group 8). For the preparation of antigen-loaded microparticles, the following materials were used: Poly ( $\varepsilon$-caprolactone) (PEC; Mw 42,500) from AldrichChemical Company (USA). Poly(D,L-lactide-co-glycolide) with a monomer ratio of 50:50 (PLGA 502; Resomer® RG 502) from Boehringer Ingelheim, Germany. PNAG-loaded microparticles were prepared (size close to $2.00 \mu \mathrm{m}$ ) using Total Recirculation OneMachine System (TROMS) [34]. The quantification of $\mathrm{NaOH}$ hydrolysed antigen was carried out by an indirect ELISA. Encapsulation efficiency for PEC and PLGA 502 microparticles was $96.02 \%$ and $98.84 \%$, respectively.

Two weeks after the booster immunization (about four days after parturition), each animal was challenged in each mammary gland (gland duct inoculation) with $10^{3}$ bacteria of strain S. aureus $\mathrm{C} 195$ (ica+ and bap-, CP8) expressing a strong biofilm phenotype.

\subsubsection{Immunological, bacteriological and clinical determinations in sheep-}

Sera were collected just before immunization, then, weekly after priming and daily during nine days after challenge, for determining the level of antibodies against PNAG by indirect ELISA. Collection of milk samples and examination (color, texture, temperature, pain, size and lameness) of mammary gland was also performed daily (for nine days) after challenge. For bacteriological purposes, the number of viable CFU per $\mathrm{mL}$ of milk was determined by plating $25 \mu \mathrm{L}$ of each eight ten-fold dilution onto TSA plates, by triplicate. After logarithmic transformation, results were expressed as mean \pm standard error (s.e.). Clinical examination allowed the establishment of four categories according to severity of mastitis: good (G, healthy or with a very mild mastitis), medium (M, with moderate mastitis), damaged (D, with strong mastitis), very damaged (VD, with highly severe mastitis). Often, animals showed a progression of mastitis and were classified accordingly as either G/M (initial postchallenge period with a good health status but ending with moderate mammary lesions) or $\mathrm{M} / \mathrm{D}$ (initial post-challenge period with an intermediate health status but ending with serious mammary lesions). The establishment of these 6 categories allowed the classification of animals into three major types, according to the health status and lesion degrees, which facilitated the statistical analysis and its interpretation: Type I $(G+G / M)$, Type II $(M+M /$ D) and Type III (D + VD). When an animal died from mastitis within the 9 day postchallenge period, the $\log \mathrm{CFU} / \mathrm{mL}$ recorded at death was fixed and used thereafter for this animal till the end of the experimental period.

\subsection{Statistical analysis}

A Chi square test was used to compare the proportion of animals with lesions between the vaccinated groups and the control group. A repeated-measure analysis of variance was 
applied for antibody titer as well as bacterial cell count statistical comparisons. A KaplanMeier survival analysis was applied to generate a Cumulative Survival Plot. Statistical comparisons between survival curves were performed by the Log-Rank test (once verified the parallelism of the survival curves), using the StatView ${ }^{\circledR}$ program for Windows (version 5.0, SAS ${ }^{\circledR}$ Institute Inc.).

\section{Results}

\subsection{PNAG/Biofilm production by the isolates used in immunization and challenge}

According to serum absorption and the different serological assays (AGID, 1D-and 2D IEP, dot blot, ELISA), PNAG was the only molecular species in the extracellular matrix obtained distinguishing strong from weak biofilm phenotypes in each isolate and it had the same antigenic specificity among different isolates. A competition ELISA that quantified PNAG in the samples used for immunization indicated that the proportion of PNAG (as detected by OD $A_{405}$ ) in the bacterial crude extract was about 1:16 (w/w) among the strong biofilm phenotype isolates used for crude bacterial extract immunization, information that was taken into account for preparation of cell-free inocula used in immunization. Biofilm formation (determined by late adherence tests) and levels of PNAG production (both highly associated in previous studies and this work, $\mathrm{P}<0.01 ; \mathrm{R}=0.86$ ) were the highest in $S$. aureus ATCC29213, followed by other strong biofilm phenotype isolates (S. aureus C104, 76 and C195). Three of these strong biofilm phenotype isolates (S. aureus ATCC29213, C104, and 76) and the corresponding weak phenotype controls (S. aureus ATCC29213 and C104) with very limited PNAG production, were used for immunization and the remaining isolate (C195 of strong biofilm phenotype) for challenge.

\subsection{Antibody response}

The antibody response to immunization in the different study groups (Table 2) was determined before challenge using a PNAG-based ELISA and categorized according to OD values obtained $\left(\mathrm{OD}_{405}\right)$. Among the bacterin-immunized groups (Fig. 1a), the highest $(\mathrm{P}<0.0001)$ antibody response was found in Group 1, the group immunized with the strongest biofilm phenotype bacteria inoculated along with aluminum hydroxide (alum), with a mean ELISA OD value $\geq 0.8$ after the first immunization. A lower but still detectable antibody production was found in the groups immunized with the same bacteria using a commercial adjuvant (Group 3) and with other strong biofilm phenotype bacteria in alum (Group 2) ( $\mathrm{P}<0.0001$ for differences between control and groups 2 or 3). Interestingly, only the groups immunized with bacterin from the strongest biofilm phenotype bacteria (Groups 1,2 and 3) maintained a mean OD value above 0.4 from week 1 to challenge. In contrast, groups immunized with bacteria of a weak biofilm phenotype in alum (Groups 4 and 5) did not produce a significant antibody response to PNAG.

The groups immunized with cell-free PNAG (Fig. 1b) showed a significant $(\mathrm{P}<0.0005)$ antibody production compared with the unvaccinated control. This response was lower $(\mathrm{P}<0.0001)$ compared with that of animals immunized with biofilm bacterins (Groups 1, 2 and 3, Fig. 1a), with the exception of Group 6, which maintained OD values in the range of 0.4-0.6. This group was inoculated with PNAG in liposomes (like Group 9, which had the lowest antibody titer), but in the presence of an E. coli bacterin in the inoculum.

\subsection{Bacterial cell counts and animal deaths}

Bacterial cell counts in milk (CFU per $\mathrm{mL}$ ) were determined for 9 days after challenge with a heterologous biofilm producing strain (S. aureus $\mathrm{C} 195$, of strong biofilm phenotype).

Groups 1, 2 and 3 had a decreased bacterial cell count throughout the study period compared with the remaining immunized $(\mathrm{P}<0.005)$ and control $(\mathrm{P}<0.0008)$ groups (Fig. 2a), 
indicating that immunization with strong biofilm phenotype bacteria conferred a significant degree of protection. A reduced number of CFU in milk was observed also in Groups 6 $(\mathrm{P}<0.07)$ and $8(\mathrm{P}<0.0001)$ compared with the unvaccinated control group (Fig. $2 \mathrm{~b})$.

However, protection in both immunized groups was lower $(\mathrm{P}<0.005)$ than that observed in Groups 1, 2 and 3. The remaining experimental groups were not protected (Groups 4, 5, 7, and 9). Overall, these results indicate that increased PNAG antibody production in immunized animals (Fig. 1) was associated with decreased bacterial counts after challenge (Fig. 2).

None of the animals in the 5 groups inoculated with bacterins (Groups 1-5) died from infection during the 9-day post-challenge period. In contrast, there were dead animals in the 4 groups immunized with purified PNAG or PNAG-containing crude extract (Groups 6-9). Animals which died from mastitis had challenge bacterial counts in milk above 7 log CFU/ $\mathrm{mL}$. Kaplan-Meier cumulative survival curves are shown in Fig. 3 for Groups 6-9. Although there were no statistically significant differences in cumulative survival between these groups, death rates were $20 \%$ in Group 8 and about $40-50 \%$ in the remaining Groups 6, 7, 9 and control.

\subsection{Health status and mammary lesions}

After observing no adverse reactions locally or systemically in any of the animals as a result of the immunization, the relationship between the degree of mammary gland lesions and antibody titers to PNAG was investigated. Results on mammary gland lesions observed 9 days post-challenge are summarized in Table 3. Mammary glands were classified into three types according to lesions and health status: Type I, with no lesions or with very mild lesions; Type II, with moderate or moderate-to-severe lesions; and Type III, with severe lesions that lead to death in some cases. As shown in Table 3, control group animals belonged to Types III (10) or II (6) but not I. None of the animals from the 5 groups immunized with bacterins (Groups 1-5) presented Type III lesions. Animals from groups immunized with cell-free antigens (Groups 6-9) had Type I, II or III lesions. Comparing lesion Types (I, II and III) found in the vaccinated groups with respect to non-vaccinated controls, the percentage of animals immunized with strong biofilm bacterins (Groups 1-3) showed the mildest lesions (16 vs. 0 animals with Type I lesions, $\mathrm{P}<0.0005$; and 0 vs. 10 animals with Type III lesions, $\mathrm{P}<0.0001$ ). In contrast, most animals ( 7 out 16 ) vaccinated with weak biofilm bacterins (Groups 4 and 5) had Type II lesions and, therefore, these lesions were more frequent than in groups immunized with strong biofilm bacterins $(\mathrm{P}<0.0001)$. In sheep immunized with cell-free antigens (Groups 6-9) a similar proportion of animals with Type II and Type III lesions was found compared with the unvaccinated control $(\mathrm{P}>0.05)$. However, Type I lesions in these vaccinated groups were more frequent $(\mathrm{P}=0.014)$ than in controls, indicating a slightly protective effect conferred by cell-free antigen immunization. When analyzed together, the two groups receiving cell-free antigens entrapped in liposomes (Groups 7 and 9 ) showed a higher ( $\mathrm{P}=0.024)$ number of Type II and Type III lesions and lower $(\mathrm{P}=0.042)$ number of Type I lesions than the other cell-free antigens immunized groups (Groups 6 and 8). Altogether, these results indicate that all the immunized sheep exhibited some degree of protection against clinical mastitis, with the best results in the groups immunized with the strong biofilm bacterins.

\subsection{PNAG antibody levels and health status}

When considering all the immunized animals involved in this study, an inverse association was found between the antibody levels (Absorbance at $405 \mathrm{~nm}$ in ELISA) reached before challenge and the bacterial counts in milk and lesions observed 9 days after challenge with S. aureus C195 of strong biofilm phenotype. As shown in Table 4, a low antibody production $(\mathrm{OD}<0.31)$ upon immunization was associated with medium $\left(10^{6}-10^{7}\right)$ - to - 
high $\left(10^{7}\right) \mathrm{CFU}$ of S. aureus per $\mathrm{mL}$ of milk, and medium (Type II) - to - severe (Type III) mastitis post-challenge. The reverse situation was found when the antibody production increased (OD $>1)$ being associated exclusively with a Type I healthy status. Overall, these results indicate that immunization with strong biofilm bacterins triggered the highest PNAG antibody levels upon immunization and conferred the highest protective effect, against infection and disease after challenge.

The relationship between PNAG antibody levels and protection against fatal mastitis was confirmed in the non-immunized (control) group after experimental challenge. As shown in Fig. 4, only the animals that produced PNAG antibodies reaching an OD in ELISA of about 0.2 (or higher) and having also a clear progression of antibody production at day 7, 8 and 9 post-challenge survived at the end of the experimental period ( 9 days post-challenge). This control group was composed of 16 sheep which did not have naturally occurring PNAGspecific antibodies before challenge and only produced them after challenge. There were 4 additional sheep which had naturally occurring antibodies to PNAG before challenge, due to natural infections, and were not included in the control or immunized groups. Thus, PNAG, presumably expressed in vivo in natural or experimental infections, triggers the production of naturally occurring IgG antibodies in sheep, as detected by ELISA.

\section{Discussion}

Previous studies have shown that immunization of ruminants either with inactivated biofilm bacteria and toxoid [35,36] or with biofilm matrix exopolysaccharides (slime) in liposomes, inoculated in the presence of toxoid and low-adherence inactivated bacteria [18] confer protection against ruminant mastitis, helping to avoid production losses. Here we have found that among ruminant isolates of $S$. aureus, the presence of PNAG is associated with a higher late adherence and capacity to produce biofilm, as is found among human clinical isolates [5,9]. Furthermore, antibodies to this polysaccharide were associated with resistance to mastitis. In contrast with the heterogeneous CP types (mainly including CP5, CP8 and CP336 [14,15]), all the strong biofilm phenotype isolates tested were, to our knowledge, of a single PNAG serotype, whose specificity could not be further fractionated by serum absorption (data not shown). This is important for vaccination purposes, because PNAG may confer a broad-spectrum protection (within and across mammalian species) against the different staphylococcal ica-dependent biofilms that lead to chronic infections.

Protection conferred by bacterins consisted of a significantly decreased bacterial cell count, which is widely known to be associated with decreased somatic cell count and increased milk production and quality, and diminished or absent mammary gland lesions. This protection could not be explained by the effect of antibodies against $\mathrm{CP}$ antigens, since immunization vs. challenge bacteria $\mathrm{CP}$ types differed.

In cell-free immunizations, the immune response could not be consistently enhanced by including non cellular components in the immunization, for example crude extracts from an additional isolate (Group 7) of the same capsular type as the challenge isolate. The reason for this could most likely be that crude extract or purified polysaccharides (including PNAG and $\mathrm{CP}$ ) need to be linked to protein or presented in the context, for example, of a bacterial cell for enabling linked-antigen recognition and the production of significant immune responses. Consistent with this was the limited antibody production triggered by the cell-free immunogens in the absence of bacterial cells. However, when PNAG soluble antigen was mixed with inactivated $E$. coli cells, the immune response against PNAG was enhanced in the surviving sheep (others died), likely because $E$. coli facilitated immune responses or promoted an environment leading to enhanced antibody production. We have previously induced an immunological response using a staphylococcal extracellular polysaccharidic 
component, referred to as slime, in liposomes in a vaccination strategy also involving inactivated bacteria and toxoid [18]. Again, inactivated bacteria may have facilitated enhanced recognition of the polysaccharide antigen. Consistent with this is the need of coupling of capsular antigens of $S$. aureus to protein carriers $[17,37]$ or their administration as a bacterin $[35,36]$ to trigger antibody production protective against mastitis (a bacterin approach may be made readily accessible to livestock industry). Similarly, PNAG has been coupled with protein carriers to immunize and protect against staphylococcal infections in laboratory animals [10]. Interestingly, PNAG- specific antibodies that mediate opsonic killing in these animals and in humans bind primarily to the non acetylated epitopes of this antigen [38,39]. $\mathrm{N}$-acetylation of $\geq 40 \%$ on PNAG will elicit primarily antibodies to the poorly-protective epitopes. However, evidence for such level of PNAG N-acetylation was not obtained for the purified PNAG used in this work (not shown). One of the reasons for an increased titre of antibody to PNAG in group 7 (that received crude antigen with highly acetylated native PNAG) compared with group 9 (immunized with purified PNAG) but a similarly poor protection may be that, in group 7 , antibodies were mainly produced to acetylated PNAG and did not have good opsonic killing activity. Interestingly, native PNAG surrounding bacteria do elicit antibodies conferring protection. Additional studies are needed to address this aspect of PNAG vaccines. According to our previous study [39], there is a preferential retention of the deacetylated form of the antigen on the cell surface. This dPNAG form is able to trigger opsonic antibodies upon immunization and has been proposed as a vaccine candidate, as the antibody produced against dPNAG favours opsonophagocytosis and results in increased survival in a murine bacteraemia model. Most likely, the protective antibodies formed in our present study using whole cells surrounded by PNAG are expected to be against dPNAG and promote opsonophagocytosis, resulting in protection against infection and mastitis.

Groups immunized with strong biofilm phenotype bacterins conferred the highest protection and groups immunized with bacterins were the only ones that conferred protection against severe disease or death (Type III mastitis) under the conditions studied. Aluminum hydroxide enhanced antibody production in strong biofilm phenotype bacterins, compared with other adjuvants tested. As expected, the bacterin that triggered the highest antibody production and conferred the highest protection against mastitis was that of the isolate with the highest capacity to produce biofilm and PNAG in this study (ATCC29213 of strong biofilm phenotype) when administered with alum. Further studies to determine if the immunity obtained against mastitis is long-lasting and how often should the immunization be done are warranted.

Because PNAG antibody production was found in the majority of control animals after challenge, it was difficult to separate the effect of immunization from that of infection and antibody production in this period (data not shown). The production of PNAG antibodies in control animals after challenge strongly suggests that PNAG is expressed by strong biofilm bacteria in vivo during mammary gland experimental infections. Also, we found animals that were excluded from this study because they had naturally occurring PNAG-specific antibodies, presumably as a result of in vivo PNAG expression from a natural infection $[40,41]$. This finding is relevant because it confirms the antigenicity of PNAG in natural ruminant mastitis infections involving in ica+ isolates.

Possibly, as shown in other PNAG studies [10,38], PNAG-specific IgG antibodies opsonize PNAG bacteria, favoring phagocytosis and leading to resistance to fatal disease. Both main IgG subclasses, $\operatorname{IgG} 1$ and $\operatorname{IgG} 2$, may play an important role in sheep against mastitis: $\mathrm{IgG} 1$ is actively transported into the non-inflamed gland from serum to milk and binds macrophages commonly present in this gland, whereas $\operatorname{IgG} 2$ is cytophilic for neutrophils, 
reaching high levels in serum in the course of infection and then being transferred from serum to the inflamed gland through transudation [18].

The ovine strong biofilm phenotype isolates used in this work were ica-positive but reverted to the weak biofilm phenotype if the selection pressure for adherence was discontinued upon repeated subcultures. Stable strong biofilm phenotypes have been described (S. aureus strain ISP479c; [42]). However, stable strong biofilm phenotypes such as that of the human isolate S. aureus 15981, that for unknown reasons produces PNAG in a stable manner, have been found only in a minority of ica-positive bacteria whose biofilm is ica-dependent [43]. This work encourages the search for strains displaying this stable phenotype, as they could be candidates for developing commercial staphylococcal vaccines delivered to ruminants in the form of biofilm bacterin. We are currently analyzing whether regulators already identified as important for biofilm formation in S. aureus, such as SarA [44,45], IcaR and TcaR [46,47] and $\sigma^{\mathrm{B}}$ are involved in the stabilization of PNAG production.

\section{Acknowledgments}

Financed by Comisión Interministerial de Ciencia y Tecnología CICYT (PETRI 95-0235-OP and BIO 99-0285). Gobierno de Navarra Núm. IIQ010449.RI1 and NIH grant R01 AI46706-06. We are thankful to Dr. C. Gamazo (University of Navarra) for help in the preparation of liposomes and Dr. V. Martínez-Merino (Public University of Navarra) for contributing to the analysis of PNAG samples. Sincere acknowledgements to personnel from the Animal Care Unit of the CITA-DGA (Zaragoza, Spain) for help with field isolates and clinical evaluations, and Dr. L. Sanchez for discussion on PNAG purification methods.

\section{References}

1. Clarke SR, Foster SJ. Surface adhesions of Staphylococcus aureus. Advances in microbial physiology 2006;51:187-224. [PubMed: 17010697]

2. Costerton JW, Stewart PS, Greenberg EP. Bacterial biofilms: a common cause of persistent infections. Science 1999;284:1318-1322. [PubMed: 10334980]

3. Kampen AH, Tollersrud T, Lund A. Staphylococcus aureus capsular polysaccharide types 5 and 8 reduce killing by ovine neutrophils in vitro. Infect Immun 2005;73:1578-1583. [PubMed: 15731056]

4. Monleon E, Pacheco MC, Lujan L, Bolea R, Luco DF, Vargas MA, et al. Effect of in vitro maedivisna virus infection on adherence and phagocytosis of staphylococci by ovine cells. Vet Microbiol 1997;57:13-28. [PubMed: 9231978]

5. Cramton SE, Gerke C, Schnell NF, Nichols WW, Götz F. The intercellular adhesion (ica) locus is present in Staphylococcus aureus and is required for biofilm formation. Infect Immun 1999;67:5427-5433. [PubMed: 10496925]

6. Mack D, Haeder M, Siemssen N, Laufs R. Association of biofilm production of coagulase-negative staphylococci with expression of a specific polysaccharide intercellular adhesin. J Infect Dis 1996;174(4):881-884. [PubMed: 8843236]

7. Maira-Litrán T, Kropec A, Abeygunawardana C, Joyce J, Mark G 3rd, Goldmann DA, Pier GB. Immunochemical properties of the staphylococcal poly-N-acetylglucosamine surface polysaccharide. Infect Immun 2002;70(8):4433-4440. [PubMed: 12117954]

8. Cucarella C, Solano C, Valle J, Amorena B, Lasa I, Penades JR. Bap, a Staphylococcus aureus surface protein involved in biofilm formation. J Bacteriol 2001;183:2888-2896. [PubMed: 11292810]

9. Maira-Litran T, Kropec A, Goldmann D, Pier GB. Biologic properties and vaccine potential of the staphylococcal poly-N-acetyl glucosamine surface polysaccharide. Vaccine 2004;22:872-879. [PubMed: 15040940]

10. Maira-Litran T, Kropec A, Goldmann DA, Pier GB. Comparative opsonic and protective activities of Staphylococcus aureus conjugate vaccines containing native or deacetylated Staphylococcal Poly-N-acetyl-bet-(1-6)-glucosamine. Infect Immun 2005;73:6752-6762. [PubMed: 16177353] 
11. Opdebeeck JP, Norcross NL. Comparative effect of selected adjuvants on the response in the bovine mammary gland to staphylococcal and streptococcal antigens. Vet Immun Immunopath 1984;6:341-351.

12. Watson DL, Davies HI. Influence of adjuvants on the immune response of sheep to a novel Staphylococcus aureus vaccine. Vet Microbiol 1993;34:139-153. [PubMed: 8451830]

13. Ekstedt RD, Bernhard JM. Preparation and characterization of a slime layer material produced by Staphylococcus aureus. Proceedings of the Society for Experimental Biol and Med (NY) 1973;142:86-91.

14. Lee JW, O’Brien CN, Guidry AJ, Paape MJ, Shafer-Weaver KA, Zhao X. Effect of a trivalent vaccine against Staphylococcus aureus mastitis lymphocyte subpopulations, antibody production, and neutrophil phagocytosis. Can J Vet Res 2005;69:11-18. [PubMed: 15745217]

15. von Eiff C, Taylor KL, Mellmann A, Fattom AI, Friedrich AW, Peters G, et al. Distribution of capsular and surface polysaccharide serotypes of Staphylococcus aureus. Diag Microbiol Infect Dis 2007;58:297-302.

16. Tollersrud T, Zernichow L, Andersen SR, Kenny K, Lund A. Staphylococcus aureus capsular polysaccharide type 5 conjugate and whole cell vaccines stimulate antibody responses in cattle. Vaccine 2001;19:3896-3903. [PubMed: 11427263]

17. Burgeot C, Gilbert FB, Poutrel B. Immunopotentiation of Staphylococcus aureus type 5 capsular polysaccharide co-entrapped in liposomes with alpha-toxin. Vaccine 2001;19:2092-2099. [PubMed: 11228381]

18. Amorena B, Baselga R, Albizu I. Use of liposome-immunopotentiated exopolysaccharide as a component of an ovine mastitis staphylococcal vaccine. Vaccine 1994;2:243-249. [PubMed: 8165857]

19. Nordhaug ML, Nesse LL, Norcross NL, Gudding R. A field trial with an experimental vaccine against Staphylococcus aureus mastitis in cattle. 2. Antibody response. J Dairy Sci 1994;77:12761284. [PubMed: 8046069]

20. Yoshida K, Ichiman Y, Narikawa S, Evans WB. Staphylococcal capsular vaccine for preventing mastitis in two herds in Georgia. J Dairy Sci 1984;67:620-627. [PubMed: 6715638]

21. Leitner G, Lubashevsky E, Glickman A, Winkler M, Saran A, Trainin Z. Development of a Staphylococcus aureus vaccine against mastitis in dairy cows. I. Challenge trials. 1: Vet Immunol Immunopathol 2003;93:31-38.

22. Calzolari A, Giraudo JA, Rampone H, Odierno L, Giraudo AT, Frigerio C, Bettera S, Raspanti C, Hernández J, Wehbe M, Mattea M, Ferrari M, Larriestra A, Nagel R. Field trials of a vaccine against bovine mastitis. 2. Evaluation in two commercial dairy herds. J Dairy Sci 1997;80:854858. [PubMed: 9178125]

23. Giraudo JA, Calzolari A, Rampone H, Rampone A, Giraudo AT, Bogni C, Larriestra A, Nagel R. Field trials of a vaccine against bovine mastitis. 1. Evaluation in heifers. J Dairy Sci 1997;80:845853. [PubMed: 9178124]

24. Baselga R, Albizu I, De La Cruz M, Del Cacho E, Barberán M, Amorena B. Phase variation of slime production in Staphylococcus aureus: implications in colonization and virulence. Infect Immun 1993;61:4857-4862. [PubMed: 8406887]

25. Heilmann C, Schweitzer O, Gerke C, Vanittanakom N, Mack D, Götz F. Molecular basis of intercellular adhesion in the biofilm-forming Staphylococcus epidermidis. Mol Microbiol 1996;20:1083-1091. [PubMed: 8809760]

26. Nemeth J, Lee JC. Antibodies to capsular polysaccharides are not protective against experimental Staphylococcus aureus endocarditis. Infect Immun 1995;63:375-380. [PubMed: 7821999]

27. Tollersrud T, Kenny K, Reitz AJ Jr, Lee JC. Genetic and serologic evaluation of capsule production by bovine mammary isolates of Staphylococcus aureus and other Staphylococcus spp. from Europe and the United States. J Clin Microbiol 2000;38:2998-3003. [PubMed: 10921967]

28. Karakawa WW, Fournier JM, Vann WF, Arbeit R, Schneerson RS, Robbins JB. Method for the serological typing of the capsular polysaccharides of Staphylococcus aureus. J Clin Microbiol 1985;22:445-447. [PubMed: 3930565]

29. Ouchterlony O. Air-borne infections; infection and spreading of infection in diphtheria with special reference to isolation wards. Acta Med Scand 1949;134:296-309. [PubMed: 15393006] 
30. McKenney D, Hubner J, Muller E, Wang Y, Goldmann DA, Pier GB. The ica locus of Staphylococcus epidermidis encodes production of the capsular polysaccharide/adhesion. Infect Immun 1998;66:4711-4720. [PubMed: 9746568]

31. Mack D, Siemssen N, Laufs R. Parallel induction by glucose of adherence and a polysaccharide antigen specific for a plastic-adherent Staphylococcus epidermidis: evidence for functional relation to intercellular adhesion. Infect Immun 1992;60:2048-2057. [PubMed: 1314224]

32. Collins J, Mancilulli M, Hohlfeld R, Finch D, Sandri G, Shtatland E. A random number generator based on the logit transform of the logistic variable. Comput Physics 1992;6:630-632.

33. Vitas AI, Diaz R, Gamazo C. Effect of composition and method of preparation of liposomes on their stability and interaction with murine monocytes infected with Brucella abortus. Antimicrob Agents Chemother 1996;40:146-151. [PubMed: 8787896]

34. García del Barrio G, Novo FJ, Irache JM. Loading of plasmid DNA into PLGA microparticles using TROMS (Total Recirculation One-Machine System): evaluation of its integrity and controlled release properties. J Cobtr Rel 2003;86:123-130.

35. Watson DL. Staphylococcal mastitis vaccine. Vaccine 1992;10:359. [PubMed: 1574923]

36. Watson DL, McColl ML, Davies HI. Field trial of a staphylococcal mastitis vaccine in dairy herds: clinical, subclinical and microbiological assessments. Aust Vet J 1996;74:447-450. [PubMed: 9006862]

37. Fattom AI, Sarwar J, Ortiz A, Naso R. A Staphylococcus aureus capsular polysaccharide (CP) vaccine and $\mathrm{CP}$-specific antibodies protect mice against bacterial challenge. Infect Immun 1996;64:1659-1665. [PubMed: 8613375]

38. Kelly-Quintos C, Kropec A, Briggs S, Ordorez CL, Goldmann DA, Pier GB. The role of epitope specificity in the human opsonic antibody response to the staphylococcal surface polysaccharide poly-N-acetyl glucosamine. J Infect Dis 2005;192:2012-2019. [PubMed: 16267775]

39. Cerca N, Jefferson KK, Maira-Litrán T, Pier DB, Kelly-Quintos C, Goldmann DA, Azeredo J, Pier GB. Molecular basis for preferential protective efficacy of antibodies directed to the poorly acetylated form of staphylococcal poly-N-acetyl-beta-(1-6)-glucosamine. Infect Immnun 2007;75:3406-3413.

40. McKenney D, Pouliot KL, Wang Y, Murthy V, Ulrich M, Doring G, et al. Broadly protective vaccine for Staphylococcus aureus based on an in vivo-expressed antigen. Science 1999;284:1523-1527. [PubMed: 10348739]

41. Takeda S, Pier GB, Kojima Y, Tojo M, Muller E, Tosteson T, et al. Protection against endocarditis due to Staphylococcus epidermidis by immunization with capsular polysaccharide/adhesion. Circulation 1991;84:2539-2546. [PubMed: 1959203]

42. Pattee PA. Distribution of Tn551 insertion sites responsible for auxotrophy on the Staphylococcus aureus chromosome. J Bacteriol 1981;145:479-488. [PubMed: 6257640]

43. Valle J, Toledo-Arana A, Berasain C, Ghigo JM, Amorena B, Penades JR, et al. SarA and not sigma Bis essential for biofilm development by Staphylococcus aureus. Mol Microbiol 2003;48:1075-1087. [PubMed: 12753197]

44. Beeken KE, Blevins JS, Smeltzer MS. Mutation of sarA in Staphylococcus aureus limits biofilm formation. Infect Immun 2003;71:4206-4211. [PubMed: 12819120]

45. Jefferson KK, Cramton SE, Götz F, Pier GB. Identification of a 5-nucleotide sequence that controls expression of the ica locus in Staphylococcus aureus and characterization of the DNA-binding properties of IcaR. Mol Microbiol 2003;48:889-899. [PubMed: 12753184]

46. Jefferson KK, Pier DB, Goldmann DA, Pier GB. The teicoplanin-associated locus regulator (TcaR) and the intercellular adhesion locus regulator (IcaR) are transcriptional inhibitors of the ica locus in Staphylococcus aureus. J Bacteriol 2004;186:2449-2456. [PubMed: 15060048]

47. Ma J, Cocchiaro J, Lee JC. Evaluation of serotypes of Staphylococcus aureus strains used in the production of a bovine mastitis bacterin. J Dairy Sci 2004;87:178-182. [PubMed: 14765825] 
a)

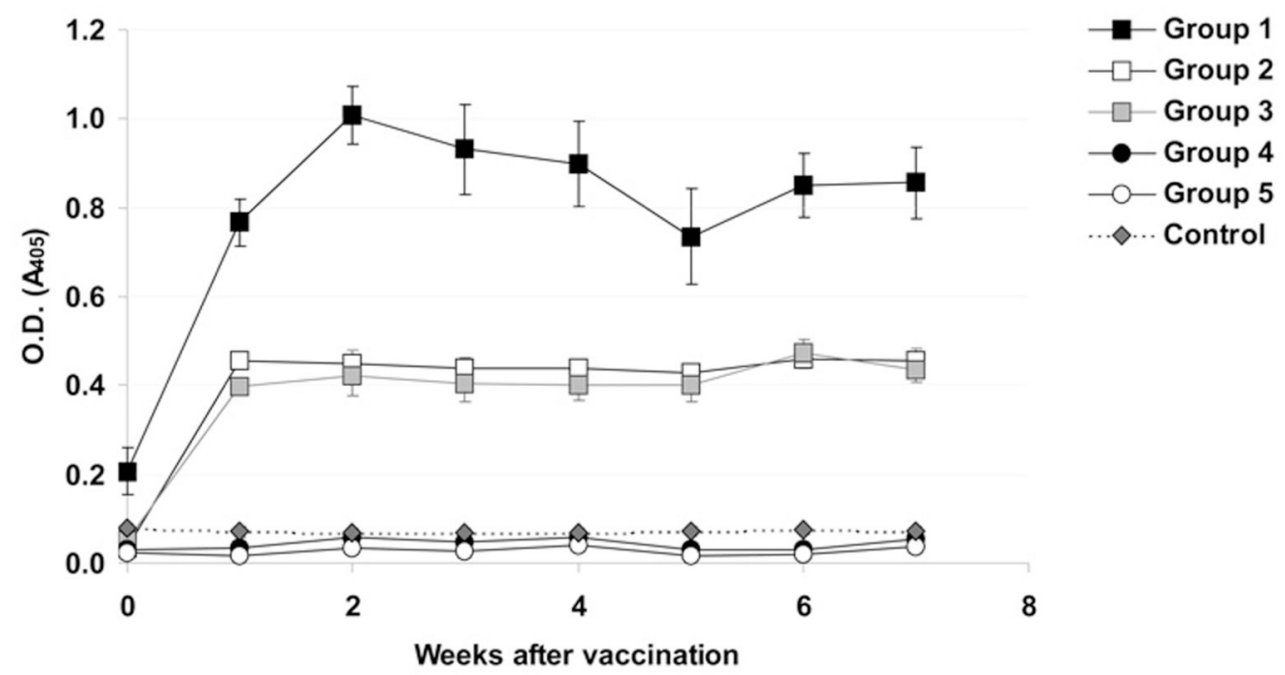

b)

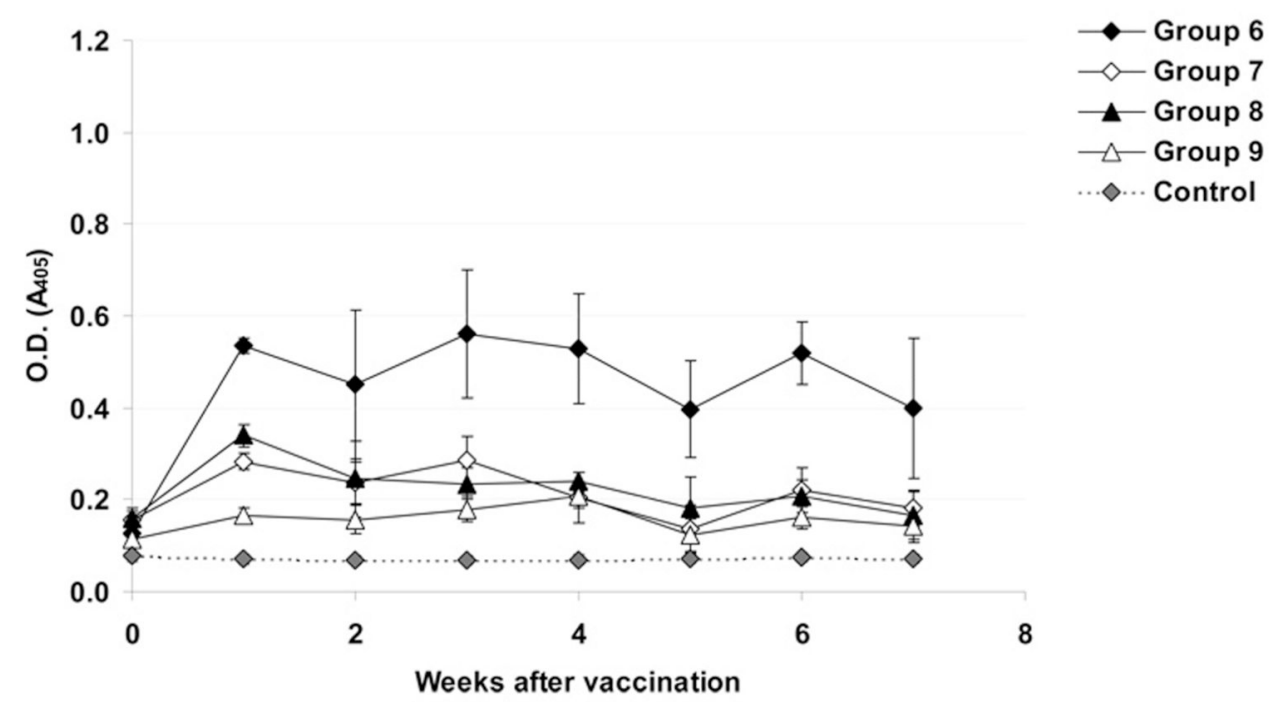

Fig. 1.

Production of antibodies (O.D., expressed as $\mathrm{A}_{405}$ mean \pm standard error, s.e.) against PNAG, as detected by ELISA. Immunization and booster were performed at weeks 0 and 5, respectively, with $S$. aureus bacterins (a) or cell-free components (b). Control animals were non-vaccinated sheep maintained under the same experimental conditions as the vaccinated sheep. None of the animals had been submitted yet to challenge with $S$. aureus. The size of ranged from 5 to 10 sheep (5 sheep in groups 6-8 and 10; 8 sheep in groups 1-5; and 10 sheep in group 9) immunized groups and was $n=16$ in the unvaccinated control. 


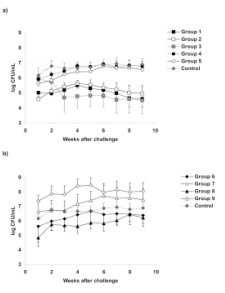

Fig. 2.

Bacterial cell counts in milk (mean $\log \mathrm{CFU} / \mathrm{mL} \pm$ s.e.) from animals of the different experimental groups during a 9 day period after challenge with $S$. aureus. Immunization was done with $S$. aureus bacterins (a) or cell-free components (b). The results obtained in the control group, experimentally infected, are included. When an animal died from mastitis within the 9 day post-challenge period, the $\log \mathrm{CFU} / \mathrm{mL}$ recorded at death was fixed and used thereafter for this animal till the end of the experimental period. 


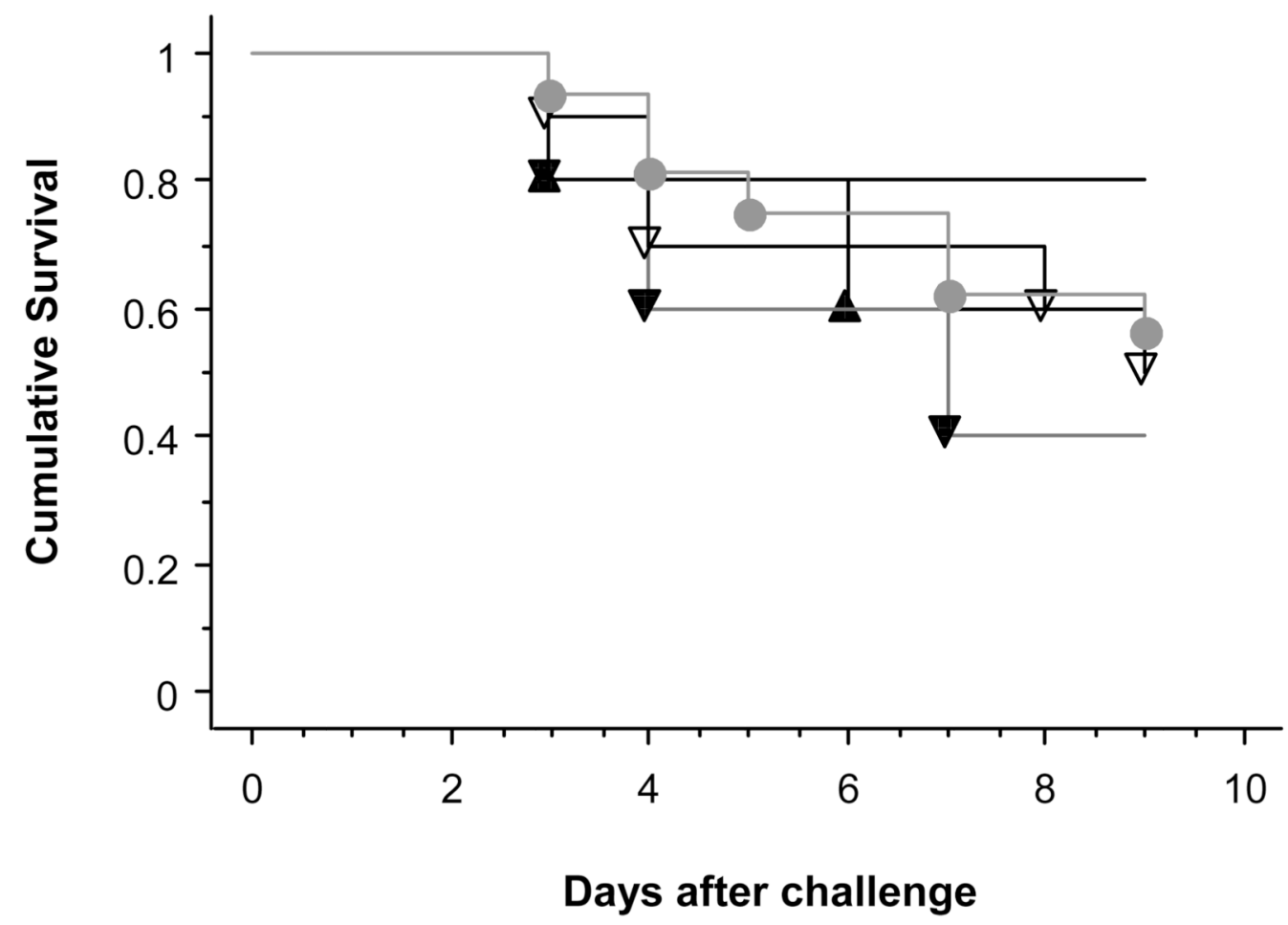

$\begin{array}{rr}\triangle & \text { Group } 6 \\ \nabla & \text { Group } 7 \\ \triangle & \text { Group } 8 \\ -\nabla & \text { Group } 9 \\ \cdots & \text { Control }\end{array}$

Fig. 3.

Kaplan-Meier Cumulative Survival Plot of cell-free immunized groups and the nonimmunized control group, after challenge with $S$. aureus. 




Fig. 4.

Antibody response (O.D., expressed as $\mathrm{A}_{405}$ mean \pm standard error, s.e.) in 16 control-group sheep after challenge with $S$. aureus, as detected by PNAG ELISA. Each column represents the daily serum sample (one column per day) obtained during the 9-day post-challenge period. Animals which did not reach the end of the experimental period and died from mastitis are indicated with the " $\dagger$ " symbol. 


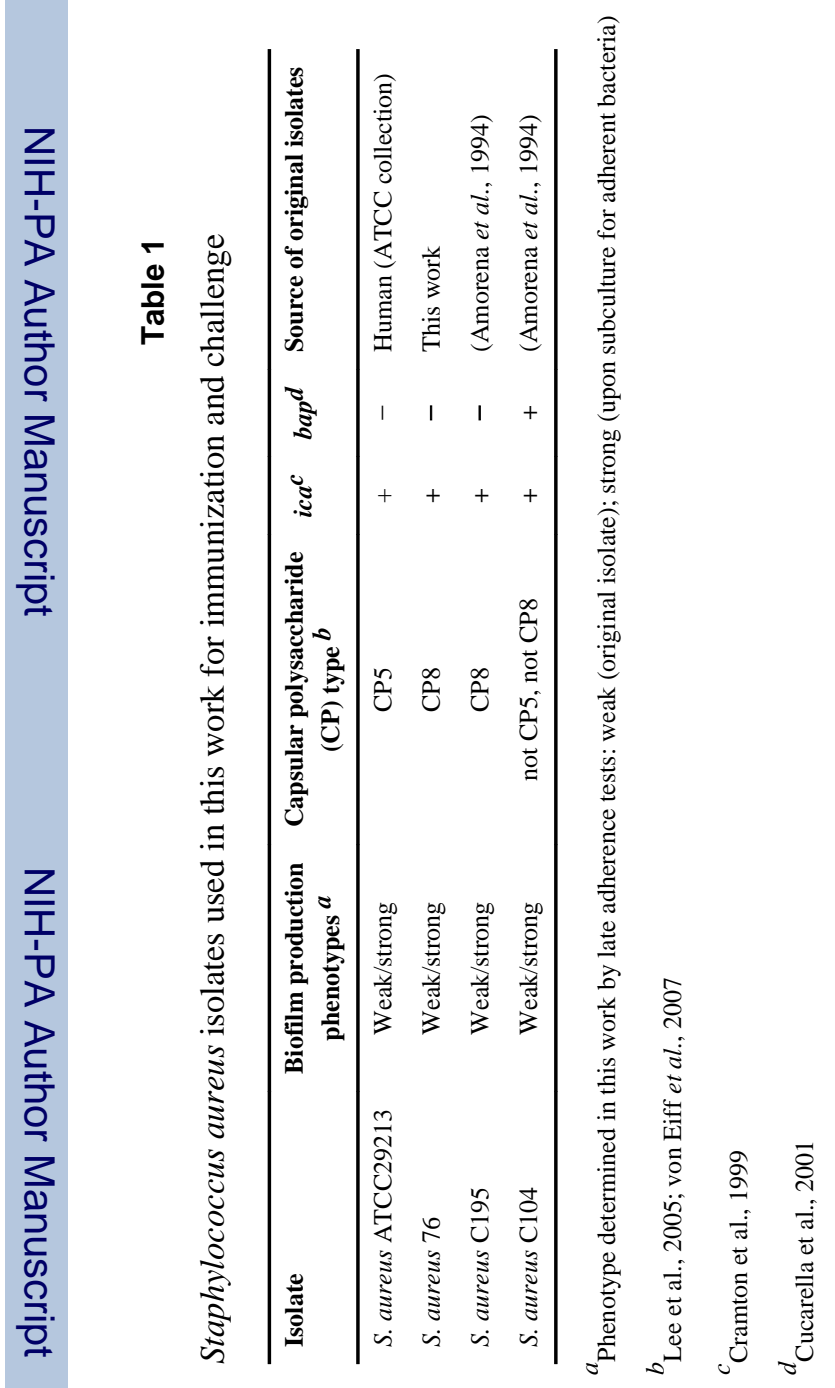

Vaccine. Author manuscript; available in PMC 2011 January 21. 
Table 2

Characteristics of the experimental animal groups and inocula used in the sheep vaccination assay

\begin{tabular}{|c|c|c|c|c|}
\hline \multirow{2}{*}{ Group of animals } & \multirow{2}{*}{ No. of animals } & \multicolumn{3}{|c|}{ Inoculum } \\
\hline & & Type & $\begin{array}{l}\text { S. aureus isolate / Biofilm phenotype / } \\
\text { CP type }\end{array}$ & Adjuvant \\
\hline 1 & 8 & Bacterin & ATCC29213 / strong / CP5 & Aluminum hydroxide \\
\hline 2 & 8 & Bacterin & C104 / strong / ND * & Aluminum hydroxide \\
\hline 3 & 8 & Bacterin & ATCC29213 / strong / CP5 & Commercial \\
\hline 4 & 8 & Bacterin & ATCC29213 / weak/ CP5 & Aluminum hydroxide \\
\hline 5 & 8 & Bacterin & C104 / weak / ND* & Aluminum hydroxide \\
\hline 6 & 5 & PNAG & ATCC29213 / weak / CP5 & Liposomes and E. coli \\
\hline 7 & 5 & PNAG-containing crude extract & $\begin{array}{c}\text { ATCC29213 / strong / CP5 + 76 / strong / } \\
\text { CP8 }\end{array}$ & Liposomes \\
\hline 8 & 5 & PNAG & ATCC29213 / strong / CP5 & Microparticles \\
\hline 9 & 10 & PNAG & ATCC29213 / strong / CP5 & Liposomes \\
\hline Control & 16 & PBS & Control & None \\
\hline
\end{tabular}

*ND: No data on capsular type (it is not CP5, not CP8) 




Vaccine. Author manuscript; available in PMC 2011 January 21. 


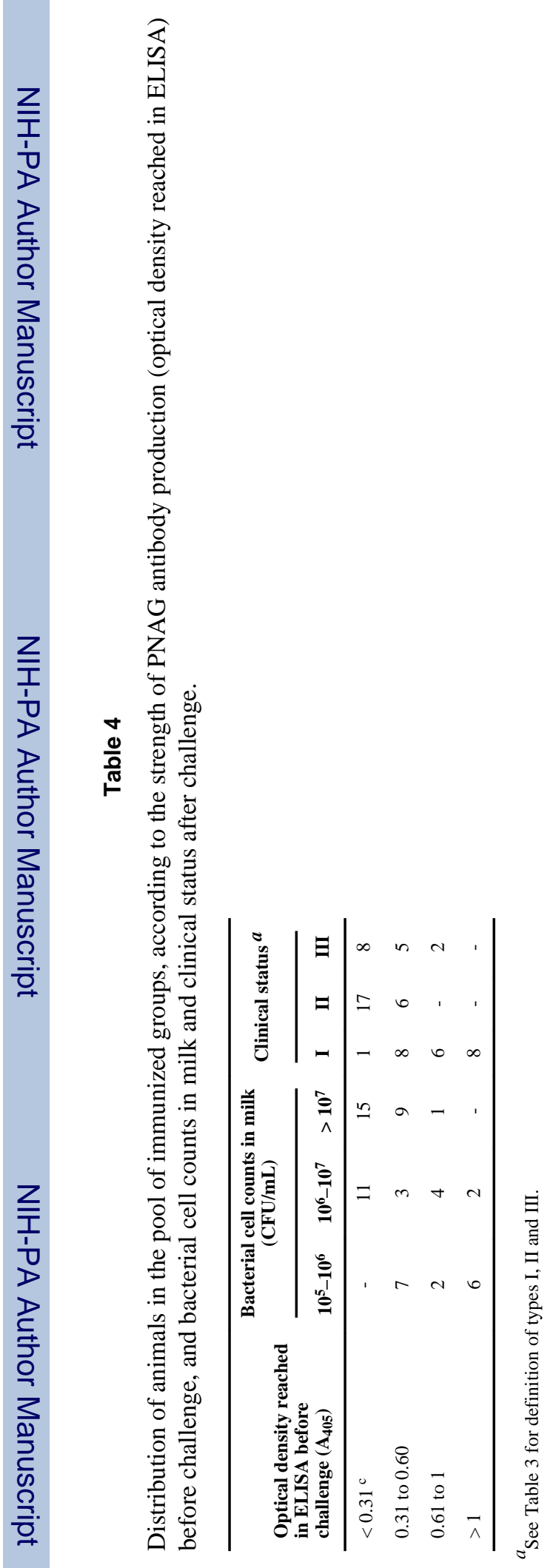

